\title{
EFFECT OF WEFT PARAMETERS ON WEAVING Performance AND Fabric Properties
}

\author{
Md. Mahbubul Haque \\ Department of Textile Engineering, Daffodil International University \\ E-mail: drhaque@daffodilversity.edu.bd
}

\begin{abstract}
Threads per inch and yarn count are some of the most important parameters that affect both weaving performance and fabric property. Experimental studies were conducted by weaving fabrics with three different picks per inch (PPI) and weft counts. The study shows that weaving performance is affected by the too high cover factor. Cover factor was calculated by dividing the threads/inch by the square root of the English cotton count and end breakage was taken as an indication of weaving performance. It was observed that when the count as well as threads/inch of one series of yarn changes the crimp\% i.e. the consumption of both series of yarns are affected. It was also observed that, as expected, when the threads/inch increases the fabric strength also increases but at higher threads/inch the gain in strength is relatively more.
\end{abstract}

Keywords: Threads, cover factor, EPI, PPI, crimp, strength, weaving performance

\section{Introduction}

Bangladesh is one of the leading exporters of ready-made garments in the world. Our ready-made garments are mainly produced from two types of fabrics e.g. (i) woven fabric and (ii) Knitted fabrics. Nearly $98 \%$ of the export oriented knitted fabrics are manufactured in Bangladesh while only $35 \%$ export oriented woven fabrics are produced in Bangladesh and the rest of the fabrics are imported. Various factors are thought to be responsible for poor performance of the woven manufacturing sector. Surprisingly in many cases the cost of local fabric is not very attractive to the garment manufacturers and they prefer to import fabric from countries like china, South Korea, Taiwan, India and Pakistan. Though our production skill is no doubt up to a good level but it does not mean that there is no possibility of further improvement.

In the competitive market the techniques of merchandising is very important. Both over pricing as well as under pricing are equally harmful for a manufacturing establishment. In merchandising of woven fabric, both the weaving performance and the quantity of yarn required for produce a particular amount of fabric are the key factors.

The work reported here shows how the weaving performance and the yarn consumption are affected when fabric (weft) parameters are changed. In this connection an attempt has been made to study the effect of weft count and picks per inch (PPI) on weaving performance and fabric properties. It is expected that this type of study will be helpful in (i) fixing cost of woven fabric more efficiently, (ii) generating a better understanding about the weaving process and finally (iii) manufacturing fabric more efficiently from the technical and technological point of view.

\section{Experimental}

The experimental work was conducted as part of the final year student's degree project. The work was conducted in 1997 in the weaving and testing laboratory of Ahsanullah University of Science and Technology (AUST).

\subsection{The experimental loom}

i. Model $=$ IC 906, ii. Origin $=\mathrm{IH}$ CHING MACHINERY CO. LTD. (Taiwan), iii. Loom R.P.M. $=200$, iv. Available Reed width $=72 "$, v. Utilized reed length (Maintained loom width) $=$ 70 ", vi. No. of head frames $=16$, vii. Reed count $=48$ stock port, viii. No. of weft accumulator $=4$, ix. Length of the rapier- a. Carrier -67 inch and Receiver - 70 inch, $x$. Take-up roller Circumference $=16 "$, xi. Motor Specification$\mathrm{RPM}=1430$, Output $=3$ HP. 


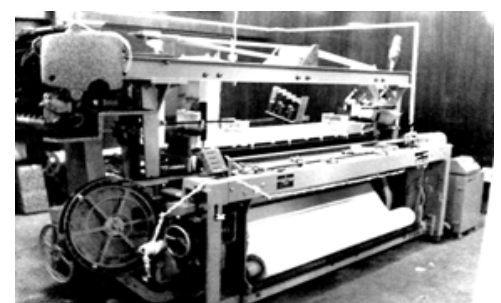

Fig. 1 The experimental loom, located in the weaving lab of AUST.

The ground and selvedge designs are as follows-

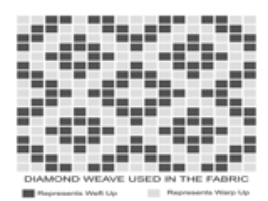

Fig. 2 Ground fabric structure

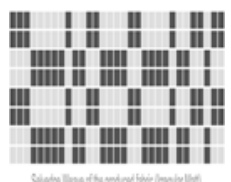

Fig. 3 Selvedge weave structure

\subsubsection{Some important feature of the experimental loom.}

\subsubsection{Weft Accumulator}

Due to the variation of speed during weft insertion, the weft yarns are subjected to high stress while withdrawing the yarn from the package. To withstand high speed and acceleration weft accumulators (see figure-4) are used. Weft accumulators stores weft yarn in advance, which allows the yarn to be withdrawn at high speed but low tension [1]. The loom is capable of using four different weft yarns hence there are four accumulators and four selectors (fugure-5) are available at the feed position and at a time only one feeder is used to feed weft yarns. There is a software program by which any suitable weft pattern can be programmed.

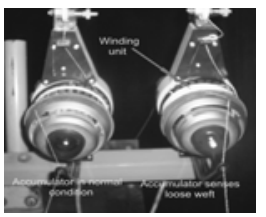

Fig. 4 Weft accumulator

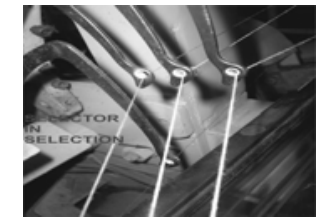

Fig. 5 Weft Selector

\subsubsection{The Rapiers}

The loom is provided with two flexible rapiers at the two sides of the loom. The rapiers transfer the weft at the centre of the shed. The weft is transferred according to the dewas or tip transfer principle.

\subsubsection{Beat-up}

The loom uses a cam beat up system, according to this system the reed gets its two and fro motion through four cams mounted in the bottom/cam shaft, two at each side (see figure -6).

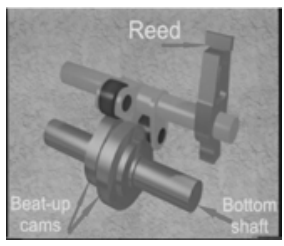

Fig. 6 Cam beat-up

\subsubsection{Let-off}

A positive mechanical type let-off mechanism is available in the experimental loom. It is possible to set any pretension in the loom and after setting a pretension the loom automatically maintain this pretension on a continuous basis.

2.1.1.5 Take-up

A six wheel take up motion is available in the loom. However the change wheel arrangement is such that a range of PPI can be obtained by using two different pick wheels. Off course a main change wheel is located in a convenient place. The loom manufacturer has supplied the three pick wheels having teeth numbers 42, 52 and 66 and these were used in the present experimental work.

\subsubsection{Warp stop motion}

The warp stop motion is of electrical type, where two bars are used as electrodes connected to a magnetic stop device. When a yarn breaks the wire drops and completes the electric circuit. The electric current passing through the circuit operates the magnetic stop device that stops the loom by using the motor brakes which is indicated by red beam of indicator lap.

\subsubsection{Weft stop motion}

Available weft stop motion in the loom was electronic sensor type. When the weft breaks the sensor detects this and stops the loom.

\subsubsection{Leno arrangement}

The leno selvedges are supplied separately from several cones at each side and are controlled independently of the main shedding mechanism. Dummy selvedges are required to hold the ends of the weft yarns until they are separated from main selvedge by a cutter. Fabric with leno selvedge has fringed edges and this false selvedge is collected separately. The machine has a positive leno apparatus. 
Table 1 Particulars of warp and weft

\begin{tabular}{|l|l|l|l|l|}
\hline Warp/weft & Fibre & Count (Ne) & Strength (N) & Extension (\%) \\
\hline Warp & Cotton & 18 & 2.78 & 3.95 \\
\hline \multirow{3}{*}{ Weft } & Cotton & 28.5 & 2.77 & 4.92 \\
\cline { 2 - 5 } & Cotton & 20 & 2.50 & 5.68 \\
\cline { 2 - 5 } & Cotton & 10 & 8.40 & 6.33 \\
\hline
\end{tabular}

\subsection{Raw materials used}

\subsubsection{Warp and Weft}

The warp beam was supplied by the loom supplier and according to them the warp beam was produced and sized in a sizing industry located at Narsingdhi.

Weft yarns of three different linear densities were bought from Narsingdhi. The details of weft were investigated and shown in Table 1. 2.2.2 Count of warp and weft

The count of the warp yarn was tested by taking some waste yarn from the weaver's beam on the loom. Several warp yarns of same length was measured and weighed to calculate the yarn count.

\subsubsection{Tensile properties of warp and weft}

Both the warp and weft yarns were tested to determine the tensile strength and elongation. The instrument used for the test was Titan Universal Strength Tester. The jaws for yarn testing were set and the maximum air pressure maintained in the compressor was 7 Bar. After opening the titan software in the computer the yarn testing standard was set to ASTM D2256 (sample length $250 \mathrm{~mm}$ and time of extension 20 seconds) and the other required parameters (pretension, break detection, rate of extension, no. of specimen) were set. Then the test was started after mounting the yarn sample between the jaws. After completion of the test a both numerical as well as graphical plot of force against extension $\%$ was automatically printed out by the computer printer attached to the instrument. The number of these plots were huge and are not presented in the report only the average of the numerical results are shown in tables $-1,8,9$ and 10 .

\subsubsection{Size Pick-up\% of the warp yarn}

Size pick up percentage was determined by desizing the warp yarns using enzyme process. In this regard 7.54 gram warp yarn sample was desized, washed and then dried. After that the sample was kept inside the weaving lab for 24 hours and then weighed again. After weighing the size pick-up percentage was calculated by using following formula:

Size pick-up in $\%=\frac{\mathrm{A}-\mathrm{B}}{\mathrm{B}}$

$\mathrm{A}=$ Weight of the sized yarn

$\mathrm{B}=$ Weight of the desized yarn

It was observed that size $\%$ of the warp yarns are $17.4 \%$

\subsubsection{Fibre content of warp and weft}

The fibre of the warp and weft yarns were tested by both burning and solubility test. Burning test of warp and weft yarn results in ashes and smell of burning paper. The solubility test of the yarn was carried out.by dissolving them in $70 \%$ sulfuric acid $\left(\mathrm{H}_{2} \mathrm{SO}_{4}\right)$ which confirms that the fibres of both warp and weft yarns were cotton (Table 1).

\section{Experimental results}

Fabrics were produced with three different weft yarns e.g. 28.5, 20 and 10 counts. For each of these wefts three different pick densities (PPI) were used. Thus nine different fabrics were produced. Investigations were carried out with these nine fabric samples during and after weaving.

\subsection{Measurement of EPI and PPI}

The EPI and PPI were tested both on loom and after relaxation by using a pick glass. Each time EPI and PPI were tested at three different positions across the width of the fabric The results are shown in the Table 3 and Table 4.

\subsection{Measurement of warp and weft cover factor}

Cover factor indicates the extent to which the area of a fabric is covered by one set of threads. The warp and weft cover was calculated by using the following formula recommended by [2]. 
Warp cover factor, $\mathrm{k}_{1}=\mathrm{n}_{1} /{ } \mathrm{N}_{1}$;

Where, $\mathrm{n}_{1}=$ Ends per inch and $\mathrm{N}_{1}=$ Cotton count

Weft cover factor, $\mathrm{k}_{2}=\mathrm{n}_{2} / \sqrt{ } \mathrm{N}_{2}$;

Where, $\mathrm{n}_{2}=$ Picks per inch and $\mathrm{N}_{2}=$ Cotton count
3.3 Effect of weft count on weaving performance (warp and weft breakages)

The weaving performance was studied in terms of warp and weft breakages and any other problems encountered during weaving. The values of warp and weft breakages for different weft counts and PPI are shown in the Table 2.

The results are shown in Table 5 and Table 6.

Table 2 Effect of weft count on warp and weft breakages

\begin{tabular}{|c|c|c|c|c|c|c|}
\hline \multirow{2}{*}{$\begin{array}{c}\text { Weft } \\
\text { Count } \\
(\mathrm{Ne})\end{array}$} & \multicolumn{2}{|c|}{$\begin{array}{l}\text { No. Pick wheel teeth }= \\
42\end{array}$} & \multicolumn{2}{|c|}{$\begin{array}{l}\text { No. Pick wheel teeth } \\
\quad=52\end{array}$} & \multicolumn{2}{|c|}{$\begin{array}{l}\text { No. Pick wheel teeth }= \\
66\end{array}$} \\
\hline & $\begin{array}{c}\text { Warp } \\
\text { Breakage }\end{array}$ & Weft & $\begin{array}{c}\text { Warp } \\
\text { Breakage }\end{array}$ & $\begin{array}{c}\text { Weft } \\
\text { Breakag }\end{array}$ & $\begin{array}{c}\text { Warp } \\
\text { Breakage }\end{array}$ & $\begin{array}{c}\text { Weft } \\
\text { Breakage }\end{array}$ \\
\hline 28.5 & & & & & & \\
\hline 20 & & & & IV & lale & \\
\hline 10 & Medium & Low & High & Low & Excessive & Low \\
\hline
\end{tabular}

Table 3 Effect of weft count on E.P.I

\begin{tabular}{|c|c|c|c|c|c|c|}
\hline $\begin{array}{c}\text { Weft } \\
\text { Count } \\
(\mathrm{Ne})\end{array}$ & \multicolumn{2}{|c|}{ No. Pick wheel teeth $=$} & \multicolumn{2}{|c|}{ No. Pick wheel teeth $=$} & \multicolumn{2}{|c|}{ No. Pick wheel teeth $=$} \\
\cline { 2 - 7 } & $\begin{array}{c}\text { On the } \\
\text { Loom }\end{array}$ & $\begin{array}{c}\text { At the } \\
\text { relaxed } \\
\text { State }\end{array}$ & $\begin{array}{c}\text { On the } \\
\text { Loom }\end{array}$ & $\begin{array}{c}\text { At the } \\
\text { relaxed } \\
\text { State }\end{array}$ & $\begin{array}{c}\text { On the } \\
\text { Loom }\end{array}$ & $\begin{array}{c}\text { At the } \\
\text { relaxed } \\
\text { State }\end{array}$ \\
\hline 28.5 & 76 & 80 & 76 & 80 & 78 & 80 \\
\hline 20 & 74 & 80 & 76 & 80 & 78 & 80 \\
\hline 10 & 74 & 76 & 76 & 80 & 78 & 77 \\
\hline
\end{tabular}

Table 4 Effect of weft count on P.P.I.

\begin{tabular}{|c|c|c|c|c|c|c|}
\hline \multirow{2}{*}{$\begin{array}{c}\text { Weft } \\
\text { Count } \\
(\mathrm{Ne})\end{array}$} & \multicolumn{2}{|c|}{$\begin{array}{l}\text { No. Pick wheel teeth }= \\
42\end{array}$} & \multicolumn{2}{|c|}{$\begin{array}{l}\text { No. Pick wheel teeth }= \\
52\end{array}$} & \multicolumn{2}{|c|}{$\begin{array}{l}\text { No. Pick wheel teeth } \\
=66\end{array}$} \\
\hline & $\begin{array}{l}\text { On the } \\
\text { Loom }\end{array}$ & $\begin{array}{l}\text { At the } \\
\text { relaxed } \\
\text { State }\end{array}$ & $\begin{array}{l}\text { On the } \\
\text { Loom }\end{array}$ & $\begin{array}{l}\text { At the } \\
\text { relaxed } \\
\text { State }\end{array}$ & $\begin{array}{l}\text { On the } \\
\text { Loom }\end{array}$ & $\begin{array}{l}\text { At the } \\
\text { relaxed } \\
\text { State }\end{array}$ \\
\hline 28.5 & 43 & 43 & 52 & 54 & 66 & 67 \\
\hline 20 & 43 & 43 & 52 & 54 & 66 & 68 \\
\hline 10 & 42 & 43 & 52 & 53 & 66 & 77 \\
\hline
\end{tabular}

Table 5 Effect of weft count on cover factor (on loom)

\begin{tabular}{|c|c|c|c|c|c|c|}
\hline $\begin{array}{c}\text { Weft } \\
\text { Count } \\
(\mathrm{Ne})\end{array}$ & \multicolumn{2}{|c|}{ Pick wheel teeth $=42$} & \multicolumn{2}{|c|}{ Pick wheel teeth $=52$} & \multicolumn{2}{|c|}{ Pick wheel teeth $=66$} \\
\cline { 2 - 7 } & Cover & $\begin{array}{c}\text { Weft } \\
\text { Cover }\end{array}$ & $\begin{array}{c}\text { Warp } \\
\text { Cover }\end{array}$ & $\begin{array}{c}\text { Weft } \\
\text { Cover }\end{array}$ & $\begin{array}{c}\text { Warp } \\
\text { Cover }\end{array}$ & $\begin{array}{c}\text { Weft } \\
\text { Cover }\end{array}$ \\
\hline 28.5 & 17.91 & 8.05 & 17.91 & 9.74 & 18.38 & 12.36 \\
\hline 20 & 17.44 & 9.61 & 17.91 & 11.62 & 18.38 & 14.75 \\
\hline 10 & 17.44 & 13.28 & 17.91 & 16.76 & 18.38 & 20.87 \\
\hline
\end{tabular}


Table 6 Effect of weft count on cover factor (At the relaxed state)

\begin{tabular}{|c|c|c|c|c|c|c|}
\hline \multirow{2}{*}{$\begin{array}{c}\text { Weft } \\
\text { Count }\end{array}$} & \multicolumn{2}{|c|}{$\begin{array}{c}\text { No. Pick wheel teeth } \\
\text { Ne })\end{array}$} & \multicolumn{2}{c|}{$\begin{array}{c}\text { No. Pick wheel teeth } \\
=52\end{array}$} & \multicolumn{2}{c|}{$\begin{array}{c}\text { No. Pick wheel teeth }= \\
66\end{array}$} \\
\cline { 2 - 7 } & $\begin{array}{c}\text { Warp } \\
\text { Cover }\end{array}$ & $\begin{array}{c}\text { Weft } \\
\text { Cover }\end{array}$ & $\begin{array}{c}\text { Warp } \\
\text { Cover }\end{array}$ & $\begin{array}{c}\text { Weft } \\
\text { Cover }\end{array}$ & $\begin{array}{c}\text { Warp } \\
\text { Cover }\end{array}$ & $\begin{array}{c}\text { Weft } \\
\text { Cover }\end{array}$ \\
\hline 28.5 & 18.85 & 8.05 & 18.86 & 10.11 & 18.85 & 12.55 \\
\hline 20 & 18.85 & 9.61 & 18.36 & 12.07 & 18.85 & 15.2 \\
\hline 10 & 17.91 & 13.59 & 18.36 & 16.44 & 18.14 & 20.87 \\
\hline
\end{tabular}

\subsection{Measurement of warp and weft crimp}

Due to the interlacing of warp and weft threads a certain amount of waviness is imparted to the warp and weft threads of a woven fabric. This waviness is called crimp. A typical

diagram of cross section of a plain woven fabric is shown in figure- 6 , the figure shows the formation of crimp of one series of yarns. Crimp is calculated by straightening the wavy yarns and then using the formula shown below $[3,4]$.

Crimp $\%=\{(1-r) \div r\} X 100$

Where,

$1=$ Length of straightened yarn (1)

$r=$ Length of yarn in the fabric $(30 \mathrm{~cm})$

Crimp is expressed as percentage and it vary from $2 \%$ to as high as $30 \%$ depending on various parameters like threads $/ \mathrm{cm}$, tex of yarns, characteristics of raw materials. In many cases the crimp\% is used to calculate the quantity of yarns required to produce a particular amount of fabric. Since crimp \% varies widely and is directly related to the yarn consumption, the information about crimp is a very important parameter for calculating the cost of woven fabric and woven merchandisers must have very good knowledge about this parameter.

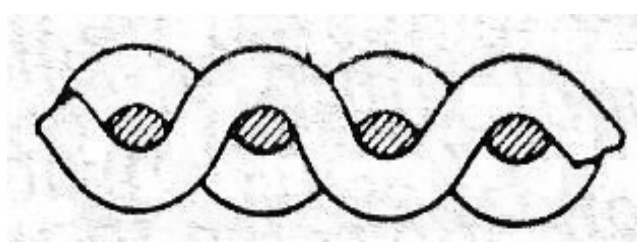

Fig. 7 Crimp or waviness in woven fabric crimp test

\section{Crimp tester}

TAUTEX Crimp Tester available in the AUST testing laboratory was used to determine the straightened length (1). It was necessary to apply a pretension for determining the straightened length. For different weft and warp yarns, it was necessary to use different pretensions using the following formula-

Pretension $(\mathrm{gm})=(0.2 \mathrm{X}$ Yarn count in Tex $)+4$. The pretension of the warp and three weft yarns are shown below;

$18 \mathrm{Ne}$ warp $=10.56 \mathrm{gm}$

$28.5 \mathrm{Ne}$ weft $=8.14 \mathrm{gm}$

$20 \mathrm{Ne}$ weft $=9.9 \mathrm{gm}$

$10 \mathrm{Ne}$ weft $=15.81 \mathrm{gm}$

\section{Sampling for crimp test}

Warp and weft yarn samples were taken from the different positions (e.g. left, right and the middle) across the width of the fabric. For each test 6 samples were tested i.e. two samples were taken from each position. The length of each sample in the fabric was $30 \mathrm{~cm}$, which is denoted as ' $r$ ' in the formula for calculating crimp.

\section{Procedure}

The yarn samples were taken out of the fabric and held very carefully so that no twist is lost. The samples were then mounted at the upper and lower jaws of the instrument. After that the pretension was applied to extend the yarn sample. This was done by moving the lower jaw slowly downwards until the digital indicator of the instrument showed the required pretension. Then the reading was taken and used as the straightened length, 1 of the yarn. The crimp $\%$ of the nine fabrics are shown in Table 7. As was mentioned earlier that there are 9 fabric samples and for each fabric sample one warp crimp $\%$ and three weft crimp \%( s) were reported. Each of the crimp \% shown in Table 7 is average of the six crimp test. 


\subsection{Measurement of fabric tensile properties}

3.5.1 Measurement fabric strength

Strength is one of the most important part of parameter of woven fabric. Strength is directly related to the useful life of a garment/and textile article. Both warp and weft way strength and elongation of the fabric was investigated by using Titan Universal Strength Tester available in the AUST textile testing lab. The specimen size was (Length $X$ Width $=14 \times 7.62 \mathrm{~cm}$ ). The test results are shown in the Table 8 .

3.5.2 Measurement of Individual yarn strength/ Fabric assistance
For analytical purpose and as a matter of interest it was decided to study the individual weft yarn strength both before and after weaving. To obtain yarn strength before weaving, single yarn from the cone was tested in the titan strength tester, and to get single yarn strength after weaving, fabric strength were tested and then the strength was divided by the number of yarn in the corresponding fabric samples. The results have shown in the Table 9.

3.5.3 Measurement of fabric extension \%

From the tensile strength test results describe in 3.5.1, the elongation at break or percentage of extension of the fabric samples before break were obtained and shown in Table 10.

Table 7 Effect of weft count on warp and weft crimp

\begin{tabular}{|c|c|c|c|c|c|c|}
\hline $\begin{array}{c}\text { Weft } \\
\text { Count (Ne) }\end{array}$ & \multicolumn{2}{|c|}{$\begin{array}{c}\text { No. Pick wheel } \\
\text { teeth }=42\end{array}$} & \multicolumn{2}{c|}{$\begin{array}{c}\text { No. Pick wheel teeth } \\
=52\end{array}$} & \multicolumn{2}{c|}{$\begin{array}{c}\text { No. Pick wheel teeth } \\
=66\end{array}$} \\
\cline { 2 - 7 } & $\begin{array}{c}\text { Warp } \\
\text { Crimp }\end{array}$ & $\begin{array}{c}\text { Weft } \\
\text { Crimp }\end{array}$ & $\begin{array}{c}\text { Warp } \\
\text { Crimp }\end{array}$ & $\begin{array}{c}\text { Weft } \\
\text { Crimp }\end{array}$ & $\begin{array}{c}\text { Warp } \\
\text { Crimp }\end{array}$ & $\begin{array}{c}\text { Weft } \\
\text { Crimp }\end{array}$ \\
\hline 28.5 & 3.43 & 5.2 & 3.53 & 7 & 5.13 & 8.33 \\
\hline 20 & 3.53 & 7.1 & 4.66 & 7.33 & 5.78 & 8 \\
\hline 10 & 6.76 & 5.1 & 7.88 & 7.66 & 11.2 & 4.83 \\
\hline
\end{tabular}

Table 8 Effect of weft count on fabric strength [Force required to break the specimen $(\mathrm{N})$ ]

\begin{tabular}{|c|c|c|c|c|c|c|}
\hline \multirow{2}{*}{$\begin{array}{c}\text { Weft } \\
\text { count } \\
(\mathrm{Ne})\end{array}$} & \multicolumn{2}{|c|}{$\begin{array}{c}\text { Pick wheel teeth } \\
=42\end{array}$} & \multicolumn{2}{l|}{ Pick wheel teeth $=52$} & \multicolumn{2}{|c|}{ Pick wheel teeth $=66$} \\
\cline { 2 - 7 } & Warp & Weft & Warp & Weft & Warp & Weft \\
\hline 28.5 & 786.61 & 317.29 & 802.09 & 434.49 & 798.87 & 569.85 \\
\hline 20 & 786.87 & 383.56 & 794.15 & 487.92 & 772.03 & 607.57 \\
\hline 10 & 804.67 & 1095.53 & 738.45 & 1371.89 & 670.44 & 1524.83 \\
\hline
\end{tabular}

Table 9 Effect of Fabric assistance on individual weft yarn strength [Force required to break the specimen $(\mathrm{N})$ ]

\begin{tabular}{|c|c|c|c|c|}
\hline $\begin{array}{c}\text { Weft count } \\
(\mathrm{Ne})\end{array}$ & $\begin{array}{c}\text { Single yarn } \\
\text { Strength }(\mathrm{N})\end{array}$ & $\begin{array}{c}\text { No. Pick wheel } \\
\text { teeth }=42\end{array}$ & $\begin{array}{c}\text { No. Pick wheel } \\
\text { teeth }=52\end{array}$ & $\begin{array}{c}\text { No. Pick wheel } \\
\text { teeth }=66\end{array}$ \\
\hline 28.5 & 2.77 & 2.52 & 2.78 & 2.88 \\
\hline 20 & 2.50 & 3.04 & 3.13 & 3.07 \\
\hline 10 & 7.70 & 8.40 & 8.69 & 8.79 \\
\hline
\end{tabular}

Table 10 Effect of weft count on fabric extension \%

\begin{tabular}{|c|c|c|c|c|c|c|}
\hline \multirow{2}{*}{$\begin{array}{c}\text { Weft count } \\
(\mathrm{Ne})\end{array}$} & \multicolumn{2}{|c|}{ Pick wheel teeth $=$} & \multicolumn{2}{c|}{ Pick wheel teeth $=$} & \multicolumn{2}{c|}{ Pick wheel teeth $=$} \\
& \multicolumn{2}{|c|}{42} & \multicolumn{2}{|c|}{52} & \multicolumn{2}{c|}{66} \\
\cline { 2 - 7 } & Warp & Weft & Warp & Weft & Warp & Weft \\
\hline 28.5 & 9.53 & 10.56 & 9.5 & 14.20 & 10.91 & 14.36 \\
\hline 20 & 10.62 & 14.45 & 11.09 & 15.4 & 12.17 & 16.31 \\
\hline 10 & 13.68 & 16.48 & 14.58 & 18.26 & 16.38 & 16.22 \\
\hline
\end{tabular}




\section{Discussion of Results 4.1 Weaving performance}

In order to evaluate the weaving performance the idea of warp and weft cover factor was thought to be important. Therefore the warp and weft cover factors were calculated as mentioned in section 3.4 the results are shown in Table 5 and 6 . It can be seen that the warp cover factor remains almost same because both warp density and warp count were constant during the study, except slight increase at higher PPI. The weft cover factor was different for the nine fabrics due to change of weft count and pick density. It will be seen in Table 5 and 6 that the weft cover factor varies from 8 (finest count and lowest PPI) to 20 (for coarsest count and highest PPI). During weaving it was observed that weaving becomes more and more difficult as the weft cover factor increases. From our practical experience about the cover factor of various types' woven fabrics, it may be concluded that for satisfactory weaving in the loom there must be certain minimum cover factor of warp and weft and normally the warp cover factor is much greater than weft cover factor. Normally the warp cover factor lies within the range of 18 to around 30 or even more in some cases while the weft cover factor is around 11 to 19 [1]. For satisfactory weaving a certain combination of warp and weft cover factor is essential. From the experience gathered during weaving, it seems that for the present combination 12 to 14 was the ideal weft factor and beyond that weaving was difficult. Weaving performance at 20 weft cover factor was completely unsatisfactory which can be seen in Table 2 that the warp breakage was higher for 16.76 and 20.87 cover factors. This probably due to the fact that at this higher cover factor both weft count and PPI were higher so that the warp crimp went up (e.g. 7.88 and 11.2) for the above two cover factors. At higher crimp the warp tension also went up and probably broke the warp yarns.

\subsection{Effect of weft count on yarn crimp}

Table 7 shows that yarn crimp is significantly affected by the thread count and their pick density. The Table also shows that as the weft count decreases the warp crimp increases.

This is probably due to the fact that coarser weft yarn is more rigid; as a result the warp yarns bend more than that occurred for finer weft yarn. Due to higher warp crimp the consumption of warp yarn would be higher. Probably due to increase in warp consumption the warp tension should go up. If warp tension increases the warp crimp will decrease and weft crimp will increases [6]. Thus, during weaving, a cyclic increase and decrease of warp and weft crimp will take place though the change would not be very high. However in relaxed fabric the case is different as there is no warp tension.

4.3 Effect of weft count on Fabric Strength [Force required to break the specimen $(\mathrm{N})$ ]

Table 8 shows that with decreasing weft count, the fabric strength in weft direction increases rapidly. This is because the strength of finer weft yarn is lower than that of coarser weft. It is also seen in the Table and figure, as expected that the strength of fabric having higher PPI is greater than fabric having lower PPI.

4.4 Effect of fabric assistance on individual yarn strength [Force required to break the specimen $(\mathrm{N})]$

It was mentioned in section 3.5.2 that single weft yarn strength was calculated using two different ways. It was observed (Table 9) that single yarn strength calculated from the fabric strength is always greater than that of the single yarn strength. This is because the strength of the yarn while in the fabric is assisted by some other factors like the cohesive forces of the adjacent yarns and the force due to the interlacement of yarns. This additional yarn strength is regarded as "fabric assistance". It can be seen in the Table 9 that the fabric assistance increases as the pick density increases.

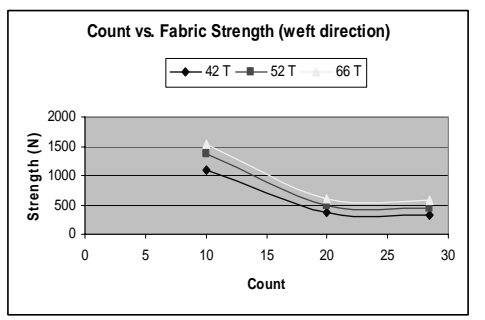

Fig. 8 Effect of weft count on fabric strength

This could be an interesting finding for both fabric as well as fashion designer because 
normally they generate greater strength by using stronger yarns and stronger yarns are costly yarns. According to the finding of Table 9 shows that we can generate a relatively stronger fabric by increasing threads/inch. The strength of very lighter fabrics can also be increased by increasing the threads/inch.

\subsection{Effect of weft count on Fabric Extension \%}

Table 10 shows that with increasing both weft density (i.e. PPI) and weft count (i.e. diameter) fabric extension increases. The reason for this may be individual weft yarn extension apart from this the crimp is directly related to the extension of the fabric. In fact fabric extension is summation of both yarn extension and corresponding crimp of yarn in the fabric. This is the reason why extension of fabric is significantly greater than that of corresponding extension of yarns.

\section{Conclusion}

The project study leads to many questions as well as related answers. The cover factor which is related to both P.P.I. and weft count and has significant effect on the weaving performance. The weft count (linear density) affect both warp and weft crimp significantly. It was also observed that (i) remaining all other parameters same, the consumption of both warp and weft will increase if the count/(diameter) of warp or weft or EPI or PPI increases. In fact a theory can be proposed that the consumption of one series of yarn of the woven fabric is directly related to the coarseness and density of the other series of yarn, (ii) as the count (diameter) and density of weft increases the weft cover factor increases for which weaving becomes more and more difficult. (iii) with increase in PPI for the same weft count the fabric strength increases. It is expected that the outcome of the study will contribute to the better understanding of the booming export oriented woven RMG sector of the country.

\section{References}

[1] M. K. Talukdar, P. K. Sriramulu and D. B. Ajgaonkar, "Weaving-Machienes Mechanisms Management" Mahajan Publishers Private Limited 1998.

[2] Pierce, F.T; "The Geometry of Cloth Structure" The Journal of The Textile Institute, March 1937. p. 45.

[3] A.T.C Robinson and R. Marks; Woven Cloth Construction; A Textile Institute Publication.

[4] Booth, J.E., "Principles of Textile Testing" NewnesButterworths.

[5] Haque, Md. Mahbubul M.Sc. thesis 1991, University of Manchester Institute of Science and Technology (UMIST), U.K. 